\title{
Milli Mücadele Dönemi Türk-Sovyet İlişkilerinde Kafkas Seddi Meselesi
}

\section{Ömer Erden ${ }^{*}$}

\section{Özet}

Milli Mücadele sürecinde Ankara Hükümeti'nin yardım alabileceği tek büyük devlet Sovyet Rusya idi. Ancak Sovyet Rusya'nın Ermenistan'ı himaye eder tavrı, bu yardımın önündeki en büyük engeldi. Gümrü Antlaşması sonrası İngiltere-Fransa'nın Ankara Hükümeti'ne yakınlaşma çabaları Sovyet Rusya'yı oldukça endişelendirdi. Ankara'nın İngiltere ve Fransa ile anlaşarak kendilerine karşı cephe alacağını düşünen Sovyet Rusya buna engel olmaya çalıştı. Bu durum Ankara Hükümeti'nin Misak-ı Milli dâhilin Sovyet Rusya ile Moskova Antlaşması'nı imzalamasında oldukça etkili oldu.

Anahtar Kelimeler: Kafkasya, Sovyet Rusya, Bolşevizm, Milli Mücadele.

\section{Caucasus Frontier's Issue in Turkish-Soviet Relations During the Turkish War of Independence}

\section{Abstract}

The Soviet government was one of the only big power that the Turkish government could get support from during its Independence War. However, the Russian government tended to protect the Armenians which created tension between the Turks and Russians. After Treaty of Alexandropol, the close relations between Britain-France and Turkey alarmed the Russian government. The Soviets feared that Ankara would become an ally with Britain and France against the Russian government, which Moscow tried to prevent. This situation helped the Turkish government to sign Turco-Soviet Friendly Agreement and maintain its National Pact (Misak-ı Milli).

Keywords: Caucasia, Soviet Russia, Bolshevism, War of Independence.

Doç. Dr., Ordu Üniversitesi, Fen Edebiyat Fakültesi, Tarih Bölümü, academicien25@hotmail.com. (ORCID ID: 0000-0003-4045-2426)

(Makale Gönderim Tarihi: 05.07.2017, Makale Kabul Tarihi: 11.08.2017)

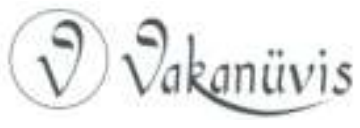




\section{Giriş}

20. yüzyıl başlarında Çarlık Rusyası ekonomik olarak oldukça zor bir durumdaydı. 1905'te Japonya karşısında ağır bir yenilgiye uğraması, Rusya'daki sıkıntıları daha da arttırdı. Birinci Dünya Savaşı'na, Boğazlar bölgesine yerleşme ve Osmanlı Devleti'nin doğu topraklarını ele geçirme hayalleri ile İtilaf Devletlerinin safında giren Çarlık Rusyası, Almanya karşısında ağır mağlubiyetler yaşadı. Bu mağlubiyetler Rusya'daki karışıklıkların daha da artmasına ve Çarlık rejiminin sona ermesine neden oldu. Ekim ihtilali ile iktidarı ele geçiren Bolşeviklerin ilk işi İttifak Devletleri ile bir an önce barış yapmak oldu. Brest-Litovsk Antlaşması ile Rusya savaştan çekildi. Bu antlaşma ile Osmanlı Devleti, 1878'de kaybettiği Elviye-i Selase'yi (Kars-Ardahan-Batum) tekrar topraklarına katmayı başardı.

Rusya'daki yeni yönetim savaştan çekilirken, daha önce çarlık rejiminin imzalamış olduğu gizli antlaşmaları da dünya kamuoyuna ilan etti. Böylece çarlığın eski müttefiklerine karşı düşman olduğunu da açıkça göstermiş oldu. Zaten Bolşevik liderler her fırsatta emperyalist devletlere karşı mücadele edeceklerini açıklamaktan çekinmiyorlardı. Onlara göre en büyük emperyalist devletler ise İngiltere ve Fransa idi. Ingiltere ve Fransa ise Bolşevizmi kendileri için büyük bir tehdit olarak görüyor, Rusya'daki iç savaşı destekliyordu. Osmanlı devleti ise Birinci Dünya Savaşından yenik ayrılmış, imzalanan Mondros Ateşkes Antlaşması ile ülke yer yer işgal edilmeye başlanmıştı. Bu işgaller karşısında Türk Milleti silahına sarılarak Mustafa Kemal Paşa ve arkadaşlarının liderliğinde mücadeleye başladı. Anadolu'daki Milli Mücadele'yi ezmek için ellerinden geleni yapan İngiltere ve Fransa, adeta Türk Milletini yok etmeyi amaçlayan Sevr tasarısını hazırlayarak İstanbul'daki kukla hükümete kabul ettirmişlerdi. Bu arada İngilizlerin 16 Mart 1920'de İstanbul'u işgal ederek Son Osmanlı Mebussan Meclisi'ni dağıtmaları, Ankara'da Mustafa Kemal Paşa'nın başkanlığında Büyük Millet Meclisi'nin açılmasına zemin hazırladı. Büyük Millet Meclisi'nin Ankara'da açılmasıyla yeni Türkiye'nin de temelleri atılmış oldu. Hem Sovyet Rusya, hem de Türkiye, Ingiltere ve Fransa'ya karşı mücadele ediyordu. Düşmanların ortak olması bu iki devleti birbirine yaklaştırdı.

\section{(2) Vadenivivis}




\section{Kafkas Seddi Meselesi}

Milli Mücadele döneminde Ankara Hükümeti'nin oldukça ihtiyaç duyduğu dış yardımı alabileceği tek büyük devlet Sovyet Rusya idi. Ancak Ankara Hükümeti ile Sovyet Rusya arasındaki ilk resmi görüşmeler oldukça sancılı geçti. Sovyet Hükümeti'nin Ermenistan'ı himaye eder tavrı ve nihayetinde Ermeniler lehine Van, Muş, Bitlis'ten toprak talep etmeleri görüşmelerin kesilmesine neden oldu. ${ }^{1}$ Ankara Hükümeti Ermenistan meselesi çözülmeden Sovyetlerle ilişkilerin arzu edildiği şekilde olmayacağını anladı. Bu durum Ermenistan üzerine yapılacak olan askeri harekâtın bir an önce başlamasına neden oldu. 28 Eylül'de başlayan doğu harekâtıyla Türk Ordusu, Sarıkamış- Laloğlu hattına kadar ilerledi ${ }^{2}$ ve yaklaşık bir ay kadar bu hatta bekledi. 28 Ekim'de başlayan Doğu Harekâtı'nın ikinci safhası sonucunda Kars'ı kurtaran $^{3}$ Türk ordusu, Ermeni kuvvetlerini tamamen yenilgiye uğratarak Gümrü'yü de işgal etti. ${ }^{4}$ Ermenilerin barış istemesi ve ardından yapılan Gümrü Antlaşması ile birlikte Ermeni meselesi Türkiye açısından kapanmış oldu.

Milli Mücadele döneminde İtilaf devletlerinin Ankara Hükümeti ile ilişki kurma çabaları, Sovyet liderleri tarafından hep endişe ile takip edildi. Aslında Sovyet liderleri bu endişelerinde haksız da değillerdi. İngiltere'nin Kafkasya özel temsilcisi Albay Stokes'in eski Kafkas Seddi projesini ${ }^{5} 1920^{\prime}$ lerin sonunda tekrar canlandırma çabaları hiç de ciddiye alınmayacak gibi değildi. ${ }^{6}$ Bu projeye göre; Türkiye, Azerbaycan, Gürcistan ve Ermenistan arasında oluşturulacak bir ittifakla bölgede Sovyet yayılmasına engel olunacak, Bolşevizm tehlikesine karşı bir güvenlik hattı oluşturulacaktı. Ayrıca bu devletler arasında ekonomik işbirliği de sağlanacaktı. Her ne kadar bu proje,

\footnotetext{
${ }^{1}$ Başbakanlık Cumhuriyet Arşivi, 30-18-1-1/1-15-9, T.B.M.M. Gizli Celse Zabıtları, C. I, s .158-173.

${ }^{2}$ Kazım Karabekir, ìstiklal Harbimiz, Metis yayınları, İstanbul 1988, s.848-849.

${ }^{3}$ Hakimiyet-i Millîye, 1 Teşrin-i Sani 1336/1 Kasım 1920

${ }^{4}$ Karabekir, a.g.e., s.858.

${ }^{5}$ Salahi R. Sonyel, Türk Kurtuluş Savaşı ve Dış Politika, I, Türk Tarih Kurumu Yayını, Ankara 2014, s. 179.

6 Stefanos Yaresimos, Türk Sovyet ilişkileri, Ekim Devriminden Milli Mücadele'ye, Gözlem Yayınları, İstanbul 1979, s. 195, Salahi Sonyel, Türk Kurtuluş Savaşı ve Dış Politika, II, Türk Tarih Kurumu Yayını, Ankara 2003, s. 30-31 .
}

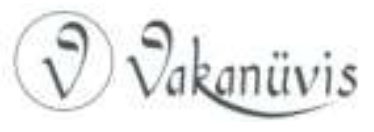


İngiliz siyasi mahfillerinde kabul görmese de Sovyet yöneticilerini hayli endişelendirdiği anlaşılmaktadır. İngiliz ve Fransızların Mustafa Kemal başkanlığında Ankara'da yeni kurulmuş olan milli hükümetle ilişki kurma çabaları Sovyet Rusya'yı bir hayli endişelendirdi. ${ }^{7}$ Zira Sovyetler bu dönemde Azerbaycan'ı yeni Bolşevikleştirmiş olmakla birlikte bölgede tam olarak hâkimiyet kuramamışlardı. 1920 yılının Eylül ayı sonunda Sovyet Dışişleri Komiseri Çiçerin, Mustafa Kemal tarafından gayri resmi olarak Moskova'ya gönderilen Halil Paşa ile yaptığı görüşmede, vaziyetlerinin Ermenilerle dahi başa çıkacak durumda olmadığını, esasen Kafkasya'daki kuvvetlerinin bir kısmını da Vrangel cephesine göndermek mecburiyetinde olduklarını söylüyordu. ${ }^{8} \mathrm{Bu}$ dönemde Sovyet ordusunun büyük kısmı bir taraftan General Vrangel'e karşı mücadele ederken diğer taraftan da Lehistan cephesinde savaşıyordu. Bu nedenle Sovyet Rusya'nın Kafkasya'daki durumu oldukça zayıftı. ${ }^{9}$ Bu durumu Ankara Hükümeti'nin bölgedeki askeri temsilcisi Seyfi (Düzgören) Bey de şu cümlelerle teyid ediyordu: “Bakü'de ve Bakü'den Karakilise'ye kadar Kızılları teçhizatça perişan, bakımsız buldum. Daha mûti ve yeni ruha daha mûnis yetiştirmek için efrad pek genç toplanmış." ${ }^{10}$

Bekir Sami Bey 21 Eylül 1920'de gönderdiği telgrafında şu bilgileri veriyordu:

“Ermenistan'daki muvaffakiyetimiz muhtelif cereyanlar hâsıl etti. Mamafih ekseriyet memnundur. Buranın en büyük endişesi İstanbul Hükümeti ile itilaf ve dolayısıyla İngiliz siyasetine takarrübümüzdür. Kafkasya'da ihtilal çıkarmak, Bakü'yü İngilizlerle müştereken işgalimizden cidden endişe ediyorlar. Kendilerine böyle bir şeyin mümkün olmayacağını ve İngiltere ile itilafın bizim için gayri kabil olduğunu, ancak şimdiye kadar bize karşı kullandıkları oyalama siyaseti devam ettikçe Ankara Hükümeti'nin gayri ihtiyari İngiltere ile telif-i beyn mecburiyetinde kalabilmesi ihtimali de var ve hatır olabileceğini insas ettim." ${ }^{11}$ Sovyetlerin 1921 yılı ortalarına kadar Kafkasya'da

\footnotetext{
${ }^{7}$ Cumhuriyet Müzesi Arşivi, D.2, 3036/A.

${ }^{8}$ Cumhuriyet Müzesi Arşivi, D.1, 3033/C.

${ }^{9}$ Cumhuriyet Müzesi Arşivi, D.1, 3033/E.

${ }^{10}$ Cumhuriyet Müzesi Arşivi, D.1, 3032.

${ }^{11}$ Cumhuriyet Müzesi Arşivi, D.2, 3034.
}

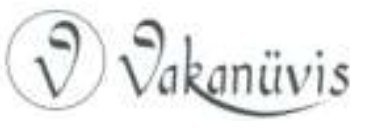


otoriteyi sağlayabilmek için yeterince kuvvetinin olmadığına dair yukarıda verdiğimiz belgelere benzer birçok belge ve bilgi mevcuttur. Kafkaslardaki bu otorite boşluğunun ise Sovyetlerin en büyük endişelerinden birisi olduğu anlaşılmaktadır.

Kazım Karabekir Paşa, Gümrü'den 27 Kasım 1920'de gönderdiği telgrafında aynı gün, Sovyet Büyük Elçisi Midivani ile üç buçuk saat süren görüşmesi ile ilgili Ankara Hükümetine bilgi veriyordu. Bu görüşmede Midivani, Sovyet Hükümeti'nin yegâne endişesinin; Ankara Hükümeti'nin İngilizlerle anlaşarak kendilerine karşı bir cephe oluşturma ihtimali olduğunu ve bu hususta sürekli propaganda yapıldığını açıkça ifade etti. Midivani, Ankara Hükümeti'nin bu siyasete meyil etmediğinden emin oldukları takdirde Anadolu'ya her türlü yardımı yapmaya hazır olduklarını, Kars vilayetinin Türkiye sınırına dâhil edilebileceğini hatta bu kâfi gelmezse Batum'un da Türkiye'ye bırakılabileceğini belirtti. Kazım Karabekir Paşa'nın tüm bunların karşılığında kendilerinden ne istedikleri sorusuna cevaben Midivani, herhangi bir askeri yardım beklemediklerini, hatta Türkiye'de Komünizmin tatbiki gibi bir emellerinin dahi olmadığını, yegâne emel ve arzularının Türkiye'nin İngilizlerle birleşmemesi olduğunu söyledi. ${ }^{12}$ Geniş yetkilerle Ankara'ya gönderilen Midivani'nin bu ifadeleri Sovyetlerin bu dönemde Türkiye'nin İngilizlerle anlaşarak kendilerine karşı cephe alacağından ne denli endişe ettiklerini açıkça gösteriyordu. Kazım Karabekir Paşa'nın Gümrü'de aynı günlerde Azerbaycan Iç̧tima-i Şura Cumhuriyeti'nin fevkalade yetkili vekili Bahdud Şahtahtinski ile gerçekleştirdiği görüşmede ise oldukça ilginç bilgilere rastlıyoruz. Bahdud Şahtahtinski bu görüşmede, Türk Ordusu'nun Gümrü'yü işgal etmesinden dolayı Sovyet Rusya'nın çok endişelendiğini belirtti. Sovyetlerin, bu hareketin Ankara Hükümeti'nin İngilizlerle anlaşarak Azerbaycan'ı istilasıyla sonuçlanacağını düşündüklerini ifade etti. Şahtahtinski'nin sarf ettiği şu cümleler ise oldukça önemliydi;

“Lenin Eylül'ün son günlerinde gizli bir celsede irad ettiği bir nutukta 'Rusya Şuralar Hükümeti, düşmanlarının bir kısmını memnun ederek bir kısmını mahf ederek galip vaziyete girmiştir. Şimdi iş Şark'a tevcih ediyor. Şark ya İngilizlerin veya Şura Hükümeti'nin mezarı olacaktır. Türkler hangi tarafın ittifakına geçerse galebe o tarafta

${ }^{12}$ Cumhurbaşkanlığı Arşivi, Eski tasnif, A.3-7-B/D.20/F.1-7.

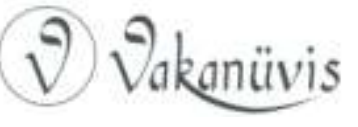


kalacaktır' demiştir. Bugün Türklerin de İngilizlerle sulh akdinin üç şekilde olacağını tasavvur ediyorlar. Birincisi İngilizlerle müttefikan Rusya aleyhine, mesela İngilizler Azerbaycan'ı Türkiye'ye vaad edebilir. İkincisi bir harekât-ı ittifak olmaz fakat Türkler, İngilizlere karşı İslam âleminde aleyhlerine propaganda yapılmasına mani olacaklarını vaad ederler. Bu da Ruslar için pek zararlıdır ${ }^{13}$. Zira Enver, Cemal vesair arkadaşlarının yaptıkları propagandalar Anadolu hükümetinin aksi ilanatı ile tesirsiz kalır. Üçüncüsü hiçbir tekeffül olmayarak alelade bir haldir. Bundan o kadar endişe etmiyorlar."14 $\mathrm{Bu}$ iki telgraftan da anlaşılacağı üzere Türkiye bu dönemde kilit konumdadır. Sovyetlerin Türkiye'ye karşı tavrı tamamen değişmiş, bırakın Ermeniler için toprak istemeyi, şartsız olarak Türkiye'ye her türlü yardımı yapmayı, Türkiye'nin istediği şekilde sınırı tanzim etmeyi kabul etmişlerdir. Sovyetlerin her ne pahasına olursa olsun, Türkiye ile anlaşmayı istediği, Ankara Hükümeti'nde etkili olan milliyetçileri etkisiz bırakarak Türkiye'yi İtilaf Bloğundan uzaklaştırmaya çalıştığı, bunun için de her türlü vaatte bulunduğu görülmektedir.

Bu dönemde Kafkasya'daki durum da bir hayli karışıktı. Moskova'ya gönderilen ikinci Türk Heyeti'nin ${ }^{15}$ Bakü'den 7 Şubat 1921'de gönderdiği telgraftan anlaşıldığı kadarıyla Rus Bolşevik Fırkasının Avrupa'daki işçilerin yakın zamanda büyük bir inkılap hareketinde bulunacağına dair beslediği ümitler boşa çıkmışı. Şimdi yegâne ümitleri şark milletlerindeydi. Bu milletler üzerinde Türkiye'nin büyük bir nüfuzu olduğu için İnkılapçı Türkiye ile sıkı sıkıya bağlanmayı ve onun hegemonyası altında Şarkta emperyalistlere karşı bir kuvvet oluşturmayı istiyorlardı. Bolşevikler Azerbaycan'da, Türkistan'da, Kırgızistan'da, Kuzey Kafkasya'da, Buhara'da, Hive'de, İran'da ve ayak bastıkları her yerde halkı çok gücendirmişlerdi. ${ }^{16}$ Bu bölgelerde genel bir hoşnutsuzluk vardı. Hatta bazı yerlerde Bolşeviklere karşı Müslümanlar harekete bile başlamışlardı. Buhara'da bu hareket çok

\footnotetext{
${ }^{13}$ Cumhurbaşkanlığı Arşivi, Eski Tasnif, A.3-7-B/D.20/F.25.

${ }^{14}$ Cumhurbaşkanlığı Arşivi, Eski Tasnif, A.3-7-B/D.20/F.25-1.

${ }^{15}$ Bu Heyet'te Moskova Büyükelçiliğine atanan Ali Fuat Paşa (Cebesoy), Yusuf Kemal Bey (Tengirşenk), Rıza Nur Bey ve askeri müşavir olarak da Saffet Bey (Arıkan) bulunuyordu. Bkz. Yusuf Kemal Tengirşenk, Vatan Hizmetinde, Kültür Bakanlığı Yayını, Ankara, 1981, s. 190-191.

${ }^{16}$ Cumhuriyet Müzesi Arşivi, D.5-3030/C.
} 
daha fazlaydı. Burada idareyi elinde tutan Rus XI. Ordusu erkânının bu konudaki endişeleri her geçen gün artmaktaydı. Azerbaycan'da ve diğer yerlerde halk sıkıntı içerisindeydi. Temel ihtiyaçlarını bile karşılayamayacak duruma gelmişlerdi ve durum her geçen gün daha da kötüye gidiyordu. Tüm bu bölgelerin halkı, umudunu Türkiye'ye bağlamıştı. ${ }^{17}$

Kafkasya Sovyet Rusya için ekonomik bakımdan da çok değerliydi. Bakü ve Grozni Sovyet Rusya için hayati öneme sahipti. Buralardan elde edilen petrol Sovyet ekonomisini ayakta tutuyordu. Sovyetler, Ingiltere ve Fransa'nın Ankara Hükümeti ile yakınlaşma girişimlerini endişe ile takip ediyor ve İngilizlerin Türklerle ittifak kurarak bölgeye hâkim olmalarından böylece de kendileri için hayati öneme sahip Bakü ve Grozni petrol kaynaklarının ellerinden alınacağından çok korkuyorlardı. Bu nedenle de Azerbaycan'ı Bolşevikleştirdikten sonra hızla hareket edip Ermenistan ve Gürcistan'ı da Bolşevikleştirmek ve Ankara Hükümeti'nin İngiltere ve Fransa ile anlaşmasına engel olmak istiyorlardı. Gürcistan, özellikle de Batum Rusya için çok önemliydi. Zira petrol fazlasını dışarıya satıp yerine ihtiyacı olan maddeleri almak için Batum limanına ihtiyacı vardı. Bu nedenle Sovyetler 1920'nin aralık ayında Ermenistan'ı Bolşevikleştirdikten sonra 1921 Şubat ayında da Gürcistan'ı Bolşevikleştirmek için harekete geçti. ${ }^{18}$

Sovyet Rusya'nın bu ülkeleri Bolşevikleştirme çabaları Kafkas Seddi projesinin daha yoğun bir şekilde tartışılmasına neden oldu. Bölgedeki Ingiliz temsilcisi Albay Stokes, Lord Curzon'a gönderdiği telgrafta; artık Türklere karşı Yunanlıları desteklemekten vazgeçilmesini, Kafkasya'da Bolşevik ilerlemesine engel olmak için Türklerin desteklenmesi gerektiğini tavsiye etmekteydi. ${ }^{19} 1921$ Şubat ayında Ankara Hükümeti bir taraftan Sovyet Rusya ile bir dostluk anlaşması yapmak ve çok ihtiyaç duyduğu para ve silah yardımını Ruslardan almak için Moskova'ya bir heyet gönderirken diğer taraftan İtilaf devletlerinin daveti üzerine Dışişleri Bakanı Bekir Sami Bey başkanlığında başka bir heyeti Londra'ya gönderiyordu. Bekir Sami Bey Londra'da İngiliz ve Fransız devlet adamları ile Türkiye, Azerbaycan, Gürcistan ve

\footnotetext{
${ }^{17}$ Cumhuriyet Müzesi Arşivi, D.5-3030/D.

${ }^{18}$ Cumhuriyet Müzesi Arşivi, D.2, 3036/A; Cumhuriyet Müzesi Arşivi, D.1, 3032.

${ }^{19}$ Yaresimos, a.g.e.,, s. 195.
}

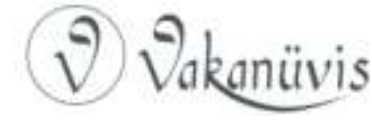


Ermenistan arasında kurulması planlanan Kafkas Seddi ile ilgili, görüşmeler yapıyor ve bu konuda neredeyse anlaşma sağlanıyordu. ${ }^{20}$ Hatta durum o kadar ciddi bir hal almıştı ki Ankara'dan Dışişleri Bakanı Vekili Ahmet Muhtar Bey ve Genelkurmay Başkanı Fevzi Paşa Sovyetlere karşı Kafkas Seddi'nin kurulmak üzere olduğunu Doğu Cephesi Komutanı Kazım Karabekir'e müjdeliyordu. ${ }^{21}$ Sovyetlerin bu konudaki endişeleri ise her geçen gün artmakta ve bu konudaki tedirginliğini sürekli dile getirmekteydi. ${ }^{22}$ Milli Mücadelenin önde gelen isimlerinin bir kısmı Kafkas Seddi'nden yana tavır koyuyor ve Bolşeviklere nefretle bakıyordu bir kısmı ise İtilaf devletlerinden hiçbir fayda sağlanamayacağını mutlaka Sovyet Rusya ile anlaşma yapılmasının gerekli olduğunu savunuyordu. ${ }^{23}$ Ankara'da tüm bu tartışmalar yaşanırken, Bekir Sami Bey'in Londra'da Kafkas Seddi'nin kurulması yönünde yaptığı görüşmeler sonuçsuz kaldı. İtilaf Devletleri'nin Sevr tasarısını biraz daha yumuşatarak Ankara Hükümeti'ne kabul ettirmeye çalışması, Londra Konferansı'nın aslında Türkiye'yi oyalamak ve Sovyet Rusya ile arasını açmak için yapılmış bir girişim olduğunu gösterdi. ${ }^{24}$ Bu durumda Ankara Hükümeti için en akıllıca yol bir an önce Sovyet Rusya ile anlaşmaktı.

Zaten tüm bu projelerin belki de hayallerin ötesinde gerçekler vardı. İngiliz ve Fransız hükümetleri hâlâ Yunan ordusunu desteklemekteydi. Bu iki devlet de Yunanistan'ın müttefikiydi ve Yunanistan İzmir'i işgal etmiş Batı Anadolu'yu da işgal etmek istiyordu, yani Türklerle savaş halindeydi. İstanbul İtilaf Devletlerinin işgali altındaydı, Güneyde İngiliz- Fransız işgali devam ediyordu. Bunlara karşılık Türk Milli Mücadelesine tek destek veren büyük devlet Sovyet Rusya idi. Sovyet Rusya da İngilizlerin, Fransızların ve onların müttefiklerinin düşmanıydı.

\footnotetext{
${ }^{20}$ Yarasimos, a.g.e., s. 210-213.

${ }^{21}$ Kazım Karabekir, a.g.e., s. 879-880.

${ }^{22}$ Cumhuriyet Müzesi Arşivi, D.1, 3045.

${ }^{23}$ Cumhurbaşkanlığı Arşivi, A-3-7-B, D-20, F-29.

${ }^{24}$ Kazım Karabekir, bu konudaki düşüncelerini 27 Mart 1921'de Mustafa Kemal Paşa'ya gönderdiği telgrafında şu cümlelerle ifade etmektedir: “Londra Konferansı'nın iç yüzünün Rus ve Gürcü harbinde Türkleri Kafkas emelleri peşine saldırıp Gürcülerle müttefikan Ruslar aleyhine harp açmak ve bu suretle Türkiye'yi ateş çemberi içinde eritmek veya hiç olmazsa Gürcüler aleyhine Ruslarla müttefikan hareketten men etmek için bir oyun olduğu artık gün gibi aşikâr oldu." Bkz. Cumhurbaşkanlığı Arşivi, A3-7-B, D-20, F-29.
}

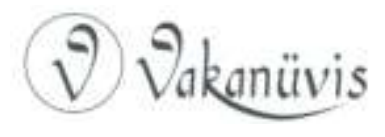


Düşmanlar birdi ve dolayısıyla Türkiye ve Sovyet Rusya doğal müttefikti. Az da olsa Ruslardan yardım alınıyordu ve Moskova'da dostluk antlaşması imzalandıktan sonra daha çok yardım alınabilecekti. Bekir Sami Bey'in Kafkas Seddi teklifi ile gitmiş olmasına rağmen Londra'dan boş dönmesi üzerine Kafkas hattı sevdasından tamamen vazgeçildi ve ${ }^{25} 16$ Mart 1921 'de Sovyet Rusya ile Türkiye arasında Moskova Dostluk Antlaşması imzalandı.

Türk Heyeti ile yapılan görüşmeler esnasında Çiçerin, Bekir Sami Beyin Londra'da Kafkas Seddi kurulması için yaptığı çalışmaları korku ve endişe ile takip ettiklerini şu cümle ile itiraf etmişti: "Bizim için de yalnız korktuğumuz Bekir Sami'ye istinad olunan sözlerin tahakkuku yani bizim aleyhimize bir ittifaktır. Bunu red etmenizden dolayı hükümetim bunu memnuniyetle görecek."26

Milli Mücadeleyi tam manasıyla anlayabilmek için Kafkasya'daki gelişmelerin göz önünde bulundurması gerekir. Bu dönemde Kafkasya karışıkık içerisindedir. Sovyet Rusya Kafkasya'ya tam manasıyla hâkim olamamış, otorite boşluğu 1921 yılı sonuna kadar devam etmiştir. Sovyet Rusya Kafkasya'da tutunabilmesi için Türkiye'nin kilit konumda olduğunu görmüş ve Ankara'ya yaklaşmaya çalışmıştır. İtilaf Devletleri için ise Bolşevizm büyük bir tehlikedir. Bolşevik rejiminin Kafkasya'ya yerleşmesi ve Anadolu'ya yayılarak İstanbul'u ve Boğazları tehdit etmesi hiç de istemedikleri bir şeydir. İngiltere-Fransa bu nedenle önce Amiral Kolçak'ı sonra General Vrangel ve Denikin'i var güçleri ile destekleyerek Sovyet iç savaşını körüklemişler ve Rus-Leh savaşını kışkırtmışlardır. Bu durum Ankara Hükümeti'ne önemli bir siyasi manevra kazandırmıştır. İtilaf Devletleri ile yapılan görüşmelerde Bolşevik tehlikesinden söz edilerek, Anadolu'nun Bolşevikleşebileceği uyarısında bulunulmuştur. Böylece İtilaf Devletleri milli çıkarlar doğrultusunda bir anlaşma yapmaya zorlanmıştır. Aynı şekilde Ankara Hükümeti, Moskova ile yapılan görüşmelerde emperyalizm tehlikesinden söz ederek, eğer gerekli yardımlar yapılmazsa ve Misak-ı Milli dâhilinde bir anlaşmaya varılamazsa, ìtilaf Devletleri ile anlaşmak zorunda kalabileceklerini, Milliyetçi kesimlerin bu konuda büyük baskı

${ }^{25}$ T.i.T.E., K.324, G.15, B.15/1; Yarasimos, a.g.e., s. 221-229.

${ }^{26}$ Cumhuriyet Müzesi Arşivi, 3045.

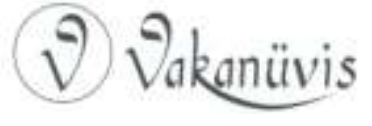


yaptıklarını, böyle bir durumda emperyalist İngiltere ve Fransa'nın Kafkasya'ya hâkim olacağını ileri sürmüştür.

\section{Sonuç}

İtilaf Devletlerinin Bolşevizm korkusu, Sovyet Rusya'nın ise Emperyalizm korkusu Ankara Hükümeti'ne iki güç arasında etkin bir denge politikası uygulama imkânı sağlamıştır. Gerek Moskova Antlaşması'na gerekse Lozan Antlaşması'na baktığımızda, başta Mustafa Kemal Paşa olmak üzere, Milli Mücadele'nin liderlerinin çok yerinde bir denge politikası izledikleri görülür. Bu denge politikasının, Milli Mücadele'nin başarıya ulaşmasında önemli katkıları olmuştur. Sovyet Rusya'dan ihtiyaç duyduğumuz yardımların gelmesinde ve İtilaf Devletleri'nin Misak-ı Milliye yakın bir antlaşmayı kabul etmelerinde izlenen bu denge politikasının oldukça etkisinin olduğunu söylememiz mümkündür. Bu nedenle Milli Mücadele dönemi araştırılırken izlenen bu denge politikasının araştırmacılar tarafından göz ardı edilmemesi gerekir.

\section{Kaynakça}

\section{Arşivler}

Başbakanlık Cumhuriyet Arşivi

Cumhuriyet Müzesi Arşivi

Cumhurbaşkanlığı Arşivi

Türk Inkılap Tarihi Enstitüsü Arşivi (T.i.T.E.)

\section{Gazete}

Hakimiyet-i Millîye

\section{Kitaplar}

Karabekir, Kazım, istiklal Harbimiz, Metis yayınları, İstanbul 1988.

Sonyel, Salahi R., Türk Kurtuluş Savaşı ve Dış Politika, I, Türk Tarih Kurumu Yayını, Ankara 2014.

Sonyel, Salahi R., Türk Kurtuluş Savaşı ve Dış Politika, II, Türk Tarih Kurumu Yayını, Ankara 2003.

Tengirşenk, Yusuf Kemal, Vatan Hizmetinde, Kültür Bakanlığı Yayını, Ankara, 1981.

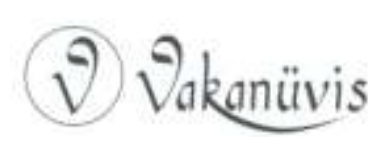


T.B.M.M. Gizli Celse Zabıtları, Cilt I.

Yaresimos, Stefanos, Türk Sovyet ilişkileri, Ekim Devriminden Milli Mücadele'ye, Gözlem Yayınları, İstanbul 1979. 